\title{
The correlation between postoperative complications of ERCP and quality of life after discharge in patients with choledocholithiasis
}

\author{
Li Huang-Fu" ${ }^{1 \#}$, Ying-Hong Qian ${ }^{1 \#}$, Ming-Jie Qian² \\ ${ }^{1}$ Endoscopy Center, The Second Affiliated Hospital of Soochow University, Suzhou, China; ${ }^{2}$ Department of Gastroenterology, The Second Affiliated \\ Hospital of Soochow University, Suzhou, China \\ Contributions: (I) Conception and design: L Huang-Fu, YH Qian; (II) Administrative support: MJ Qian; (III) Provision of study materials or patients: \\ L Huang-Fu; (IV) Collection and assembly of data: YH Qian; (V) Data analysis and interpretation: All authors; (VI) Manuscript writing: All authors; \\ (VII) Final approval of manuscript: All authors. \\ "These authors contributed equally to this work. \\ Correspondence to: Ming-Jie Qian. Gastroenterology Department, The Second Affiliated Hospital of Soochow University, 1055 Sanxiang Road, Gusu \\ District, Suzhou 215000, China. Email: qmj253253@163.com.
}

Background The treatment of choledocholithiasis by endoscopic retrograde cholangiopancreatography (ERCP) is a difficult endoscopic procedure involving a complicated surgical process. During and after ERCP, surgery-related complications may occur, and serious complications can threaten the life of the patient. This study aims to evaluate the correlation between the possible complications of ERCP treatment of choledocholithiasis and the quality of life of patients, and to provide a basis for formulating corresponding intervention measures.

Methods: Using the Gastrointestinal Quality of Life Index (GIQLI) and the MOS item short from health survey (SF-36), we conducted random telephone follow-ups of 194 patients admitted to The Second Affiliated Hospital of Soochow University who underwent ERCP for the treatment of choledocholithiasis from October 2017 to December 2020. The patients' complications symptoms and quality of life were recorded, and a comparative analysis was performed.

Results: During the hospitalization of the included 194 patients, complications occurred in 38 cases $(19.6 \%)$, including 18 cases $(9.3 \%)$ of hyperamylase, 11 cases $(5.7 \%)$ of acute pancreatitis, and 5 cases (2.6\%) of cholecystitis. There were 4 cases $(2.1 \%)$ of gastrointestinal bleeding. The SF-36 scores in the complication group were significantly lower than those in the non-complication group across various dimensions, including bodily pain (BP), general health (GH), vitality (VT), social functioning (SE), and mental health $(\mathrm{MH})$. Furthermore, the GIQLI scores in the complication group were lower than those in the non-complication group across various dimensions, including symptoms, subjective symptoms, physical function status, social activity status, as well as mental and psychological status. Multiple regression analysis showed that dimensions such as PF, BP, and subjective symptoms were more likely to be affected by hyperamylaseemia, acute pancreatitis, and cholecystitis, and the difference was statistically significant $(\mathrm{P}<0.05)$.

Conclusions: Complications after ERCP result in a poor quality of life after discharge in choledocholithiasis patients, suggesting that nurses need to take effective measures to prevent and actively treat hyperamylase, acute pancreatitis, and acute pancreatitis during the hospitalization of holedocholithiasis patients after ERCP. Common complications, such as cholecystitis, promote the recovery of patients and reduce the impact of the disease on quality of life.

Keywords: Common bile duct stones (CBDS); endoscopic retrograde cholangiopancreatography (ERCP); complication; quality of life 
Submitted May 07, 2021. Accepted for publication Jun 23, 2021.

doi: 10.21037/apm-21-1373

View this article at: https://dx.doi.org/10.21037/apm-21-1373

\section{Introduction}

Common bile duct stones (CBDS) are a common biliary disease caused by biliary tract infections, cholestasis, changes in biliary mechanics, hepatitis B virus, parasites, etc., accounting for $10-15 \%$ of patients with cholelithiasis (1). In recent years, the incidence of CBDS has shown a significant upward trend, accounting for approximately $8-20 \%$ of all gallstones patients in Western countries and about $8-10 \%$ of patients in China (2).

CBDS can cause complications such as obstructive jaundice, cholangitis, liver abscess, pancreatitis, and secondary biliary cirrhosis (3). The clinical manifestations of CBDS are complex and changeable. The ictal and interictal periods can alternate, and there is no discomfort during the interictal period. Upper abdominal pain, jaundice, chills, and high fever are usually present during the attack period, which is referred to as the Charcot triad. Hypotensive shock and neuropsychiatric symptoms are known as the Reynolds pentad. Considering the serious clinical consequences caused by CBDS, it is currently generally believed that once CBDS is discovered, it should be actively treated, regardless of whether there are related symptoms or not (4).

The treatment of CBDS mainly involves surgically removing the stones to relieve bile duct obstruction. In the past, the first choice for the treatment of CBDS was open common bile duct exploration (OCBDE), however this surgical method is traumatic, and involves a slow recovery period and long hospital stay. Over the past 20 years, with the development of endoscopic technology, endoscopic retrograde cholangiopancreatography (ERCP) has been widely used in the diagnosis and treatment of biliary and pancreatic diseases. With the continuous improvement of the technical level and the corresponding endoscopic auxiliary devices, the success rates of intubation, stone extraction, and other ERCP procedures have improved significantly. The success rates of nipple intubation and common bile duct stone extraction are more than $95 \%$ and $90 \%$, respectively. ERCP can help to explore the abdominal cavity, locate the location, size and number of stones in patients with cholelithiasis combined with choledocholithiasis during cholecystectomy and stone removal. It has a significant effect on effectively removing the stones in the affected part and reducing the damage of adjacent tissue. Therefore, it is particularly important to master the situation of the affected part before the implementation of cholelithiasis removal (5). Compared single-stage laparoscopic cholecystectomy and CBDS exploration vs. two-stage preoperative endoscopic CBDS clearance followed by laparoscopic cholecystectomy, recurrent CBDS stones occurred more commonly in patients who had undergone two-stage treatment with initial endoscopic stone clearance, followed by laparoscopic cholecystectomy (6). In recent years, with the rise of endoscopic retrograde cholangiopancreatography (ERCP) and Eport Update Sys (EUS) examinations, therapeutic ERCP has become increasingly dominant. ERCP has a wide range of indications; clinically, approximately $90 \%$ of CBDS can be processed by ERCP (7), and it is especially suitable for patients who cannot tolerate surgical procedures, such as post-cholecystectomy patients, elderly people, as well as those with poor basic conditions or numerous comorbidities. ERCP has a high stone removal success rate; the success rate of common bile duct intubation by experienced endoscopists can reach $98 \%$, and the stone removal rate can reach $85-92 \%$ (2). It offers advantages including broad indications, a high success rate, less trauma, quick recovery, and repeatability, etc. $(8,9)$, and has become one of the main treatments for CBDS.

However, ERCP has a certain risk due to its complicated operation and it is an invasive operation. It can cause recent complications such as bleeding, perforation, pancreatitis after ERCP, and late complications such as nipple stenosis, cholangitis, and recurrence of stones. The overall incidence of ERCP postoperative complications reported by domestic and foreign studies is $4-9.8 \%(10,11)$, including acute pancreatitis, bile duct infection, gastrointestinal bleeding, cholecystitis, intestinal perforation, as well as cardiovascular and cerebrovascular accidents. Among them, postoperative pancreatitis is the most common, with an incidence of $2-40 \%$ (12-14), followed by bile duct infection, which has an incidence rate of $0.35-20.04 \%$ in China $(15,16)$ and $0.1-2.1 \%$ abroad $(17,18)$. The incidence of bleeding and perforation is relatively low (1\% and $1-2 \%$, respectively) (14). In a guideline on acute cholecystitis in Japan, it was reported that the incidence of acute cholecystitis after 


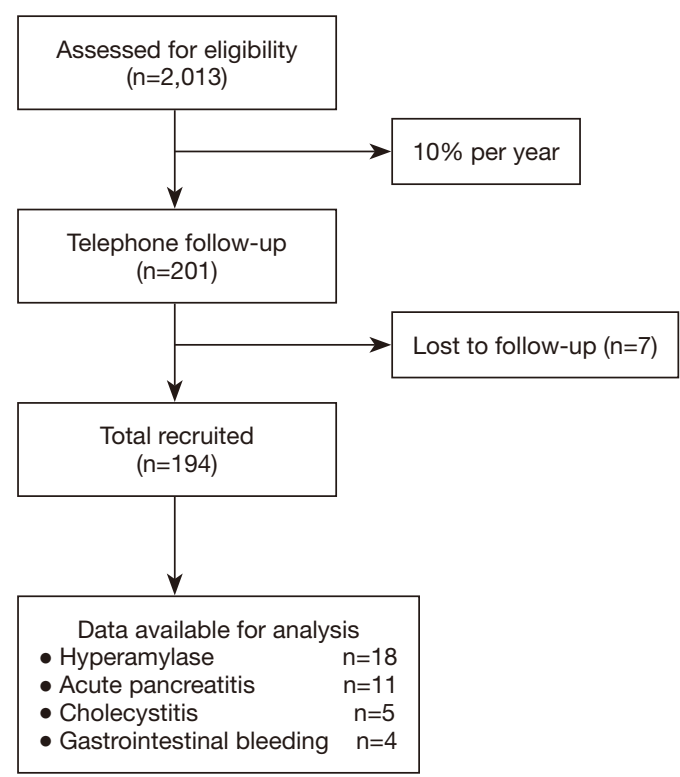

Figure 1 Study flowchart.

ERCP was $0.2-1 \%$ (19). The recurrence rate of CBDS after ERCP stone removal is approximately 4-24\% (20). Age greater than 65 years, history of biliary surgery, measures taken during ERCP and postoperative complications were independent risk factors for recurrent choledocholithiasis after ERCP (21).

At present, there are few reports on the quality of life and complication rate of CBDS patients after ERCP in China. Therefore, in order to comprehensively and objectively evaluate the treatment effect and quality of life of patients, we randomly conducted a telephone survey of 2,013 patients with CBDS who underwent ERCP in the Second Affiliated Hospital of Soochow University from October 2017 to December 2020. Based on a proportion of $10 \%$ annually, 194 cases were followed up effectively and seven cases were lost to follow-up. The report is as follows.

We present the following article in accordance with the STROBE reporting checklist (available at https://dx.doi. org/10.21037/apm-21-1373).

\section{Methods}

This study was conducted in accordance with the Declaration of Helsinki (as revised in 2013), and was approved by the Ethics Committee of the Second Affiliated Hospital of Soochow University ([2017]311). All participants provided informed consent.

\section{Subjects}

We took 2,013 cases of CBDS patients undergoing ERCP who were admitted to the Second Affiliated Hospital of Soochow University from October 2017 to December 2020 as a source, and used the random number table method to enroll $10 \%$ of these patients into the survey. The inclusion criteria were as follows: (I) patients aged 18 years and above, had normal mental and cognitive ability, and could cooperate to complete the investigation and research; (II) patients diagnosed with CBDS through ERCP, had successfully removed stones, and were confirmed as having no residual filling defect through angiography; (III) patients with good cardiopulmonary function, and did not have other chronic diseases; and (IV) all subjects voluntarily participated in this study and signed the written informed consent. The exclusion criteria were as follows: (I) pregnant or breastfeeding women; (II) those with impaired consciousness; (III) patients that had undergone previous open or laparoscopic cholecystectomy; (IV) those with no stones found during ERCP; (V) patients with malignant tumors of other systems; (VI) patients with bile duct stenosis, biliary pancreas abnormal duct confluence; periampullary and bile pancreatic duct, duodenal papillary tumors or congenital choledochal cysts, intrahepatic bile duct stones; and (VII) cases with missing clinical medical record information (see Figure 1).

\section{Data collection}

After enrollment, two trained nurses served as investigators to record the patient's gender, age, medical insurance type, education level, stone diameter, number of stones, common bile duct diameter, and other basic information, and promptly assessed the patient's complications during hospitalization and treatment information. After the patients were discharged or transferred, they were followed up by telephone on the 90th day of the enrollment survey. During the follow-up, the quality of life of the patients was investigated and entered into the electronic data collection platform (Excel; Microsoft China Co., Ltd., Beijing, China).

\section{Quality of life survey}

The gastrointestinal quality of life index (GIQLI) and the MOS item short from health survey (SF-36) were used together.

The GIQLI involves a total of 36 items: conscious 
symptom score (19 questions), social activity score (five questions), physical and physiological function score (seven questions), as well as psychological and emotional score (five questions). Each item was scored from 0 to 4 points; with a full score of 144 points and a normal reference value of 121-125 points. Higher scores signified a better health condition (22).

The SF-36 is a validated quality of life instrument for gallbladder disease recommended by the European Association for Endoscopic Surgery (EAES) (23). It involves eight dimensions, including the following 36 items: general health (GH, 5 items), physiological function (PF, 10 items), role physical (RP, 4 items), body pain (BP, 2 items), vitality (VT, 4 items), social function (SF, two items), role emotional (RE, three items), and mental health $(\mathrm{MH})$. The second item was the self-reported health change and did not participate in the calculation of the scale score. The score of each dimension adopts the percentage system, and the score conversion formula is as follows: the score of each dimension $=[$ actual score - the lowest possible score of the dimension)/the difference between the highest possible score and the lowest possible score of the dimension] $\times 100$. Higher scores indicated a better quality of life (24).

\section{Statistical analysis}

After entering the recovered scale results into the computer, score conversion was performed, and the software SPSS version 22.0 (IBM Corp. Chicago, IL, USA) was used for statistical analysis. Measurement data were described by the mean and standard deviation, and counting data were described by the frequency and percentage. Measurement data were analyzed using the $t$-test, and counting data were analyzed using the chi-square test and rank-sum test. Multiple linear regression analysis was used to correct for confounding factors, and $\mathrm{P}<0.05$ was considered statistically significant.

\section{Results}

\section{General clinical data}

A total of 2013 CBDS patients after ERCP were included in this study. Among them, 194 were followed up effectively by telephone and seven were lost to follow-up. Of these patients, there were 120 males and 74 females, aged 22-68 years, with an average age of $(49.17 \pm 13.09)$ years. The age of patients without complications was $(48.59 \pm 13.05)$ years, while the age of patients with complications was $(51.62 \pm 13.19)$ years.
Thirty-nine cases were in primary school and below, 124 cases were in secondary and higher vocational education, and 31 cases were in junior college or above. 156 cases were insured and 38 cases were uninsured. The differences in the general clinical data between the two groups were not significant.

In total, there were 62 single-stone cases and 132 cases of multiple stones, with an average CBDS diameter of $(8.12 \pm 4.34) \mathrm{mm}$, and an average bile duct diameter of $(11.18 \pm 4.07) \mathrm{mm}$. Among these, there were 55 single-stone cases and 102 cases of multiple stones without complications, with an average CBDS diameter of $(7.41 \pm 3.06) \mathrm{mm}$, and an average bile duct diameter of $(10.58 \pm 3.63) \mathrm{mm}$. Seven single-stone patients and 30 patients with multiple stones suffered complications, with an average CBDS diameter of $(11.14 \pm 6.01) \mathrm{mm}$, and an average bile duct diameter of $(13.74 \pm 5.01) \mathrm{mm}$. The average CBDS diameter and average bile duct diameter of patients with complications were significantly different from those without complications, as shown in Table 1.

During the hospitalization of the included 194 patients, 38 cases $(19.6 \%)$ had complications, including 18 cases $(9.3 \%)$ of hyperamylase, 11 cases $(5.7 \%)$ of acute pancreatitis, and five cases $(2.6 \%)$ of cholecystitis. There were four cases $(2.1 \%)$ of gastrointestinal bleeding.

\section{$S F-36$}

We compared the SF-36 scores between patients without complications and those with complications: $\mathrm{PE}$ (77.17 \pm 3.49 vs. $73.43 \pm 5.10), \mathrm{RP}(78.12 \pm 4.63$ vs. $70.05 \pm 5.86)$; BP $(79.56 \pm 3.45 v s .68 .19 \pm 3.80) ; \mathrm{GH}(75.39 \pm 4.07 v s$. $65.68 \pm 3.03) ; \mathrm{VT}(73.76 \pm 3.94$ vs. $64.43 \pm 4.11)$; SE (75.71 \pm 4.32 vs. $74.86 \pm 4.33)$; RE (72.45 \pm 5.67 vs. $69.86 \pm 5.54)$; and $\mathrm{MH}(78.54 \pm 3.54$ vs. $68.19 \pm 3.80)$, respectively. As shown in Table 2, the SF-36 scores of the complication group were lower than those of the uncomplicated group, and the differences were statistically significant (all $\mathrm{P}<0.05)$.

\section{GIQLI}

We also compared the GIQLI scores between patients without complications and those with complications: subjective symptoms $(62.38 \pm 4.76$ vs. $51.68 \pm 7.21)$; physiological function status $(16.34 \pm 4.19 v s .15 .07 \pm 4.45)$; social activity status $(13.61 \pm 2.62 v s .12 .42 \pm 3.74)$; and mental state $(15.57 \pm 2.23$ vs. $12.15 \pm 3.6)$, respectively. As shown in Table 3, the differences between the two groups were 
Table 1 Baseline characteristics of the participants in both groups $\left(\bar{x}_{ \pm \mathrm{s}}\right)$

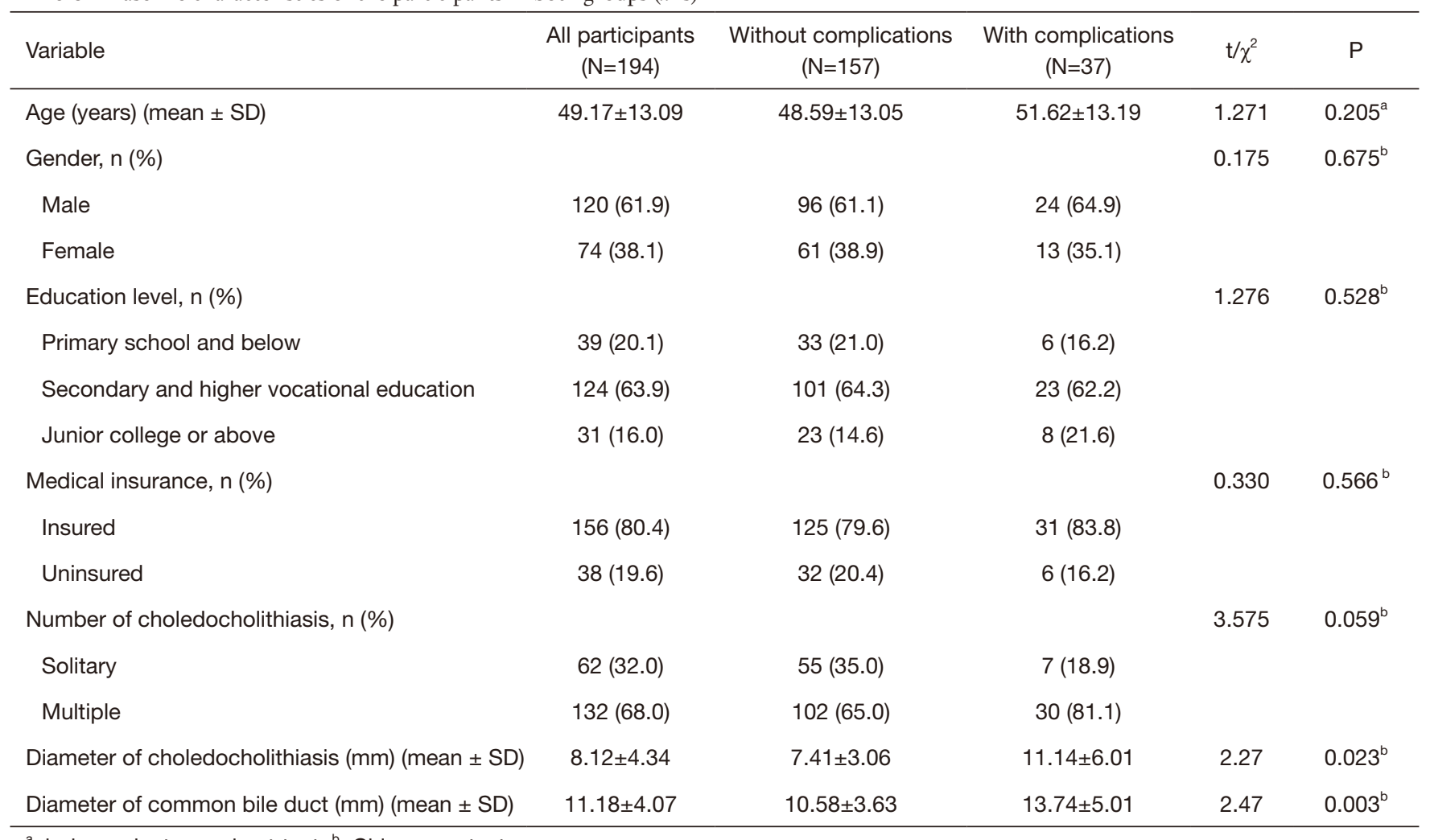

${ }^{a}$, independent samples $t$-test; ${ }^{\mathrm{b}}$, Chi-square test.

Table 2 Comparison of the SF-36 scores between the two groups $(\bar{x} \pm \mathrm{s})$

\begin{tabular}{lcc}
\hline Variable & Without complications & With complications \\
\hline PF & $77.17 \pm 3.49$ & $73.43 \pm 5.10$ \\
RP & $78.12 \pm 4.63$ & $70.05 \pm 5.86^{\mathrm{a}}$ \\
BP & $79.56 \pm 3.45$ & $68.19 \pm 3.80^{\mathrm{a}}$ \\
GH & $75.39 \pm 4.07$ & $65.68 \pm 3.03^{\mathrm{a}}$ \\
VT & $73.76 \pm 3.94$ & $64.43 \pm 4.11^{\mathrm{a}}$ \\
SF & $75.71 \pm 4.32$ & $74.86 \pm 4.33$ \\
RE & $72.45 \pm 5.67$ & $69.86 \pm 5.54$ \\
MH & $78.54 \pm 3.54$ & $68.19 \pm 3.80^{\mathrm{a}}$ \\
\hline
\end{tabular}

Compared to without complications, ${ }^{\mathrm{a}} \mathrm{P}<0.05$. GH, general health; PF, physiological function; RP, role physical; BP, body pain; VT, vitality; SF, social function; $\mathrm{RE}$, role emotional; $\mathrm{MH}$, mental health.

statistically significant.

\section{Correlation between complications and quality of life score}

The SF-36 and GIQLI scores in each dimension were
Table 3 Comparison of the GIQLI scores between the two groups $(\bar{x} \pm s)$

\begin{tabular}{lcc}
\hline Variable & Without complications & With complications \\
\hline Conscious symptoms & $62.38 \pm 4.76$ & $51.68 \pm 7.21^{\mathrm{a}}$ \\
Physiological function & $16.34 \pm 4.19$ & $15.07 \pm 4.45$ \\
state & & \\
Social activity status & $13.61 \pm 2.62$ & $12.42 \pm 3.74$ \\
Mental state & $15.57 \pm 2.23$ & $12.15 \pm 3.6^{\mathrm{a}}$ \\
\hline
\end{tabular}

Compared to without complications, ${ }^{\mathrm{a}} \mathrm{P}<0.05$.

used as dependent variables, and the occurrence of each complication was used as an independent variable to conduct multiple regression analysis. We found that the occurrence of hyperamylaseemia, acute pancreatitis, and cholecystitis significantly lowered the PF, BP, and subjective symptoms scores $(\mathrm{P}<0.05)$. See Table 4 and Table 5 for details.

\section{Discussion}

The treatment of CBDS with ERCP is a difficult endoscopic surgery method with a complicated surgical process, and 
Table 4 Multi-factor analysis of the SF-36 scores ( $\mathrm{n}=194$, Odd ratio, 95\% CI)

\begin{tabular}{lccccc}
\hline Variable & With complications & $\begin{array}{c}\text { Hyperamylasemia } \\
\text { acute pancreatitis }\end{array}$ & Acute pancreatitis & Cholecystitis & Gastrointestinal bleeding \\
\hline PF & $-5.370(-9.405--1.085)^{\mathrm{a}}$ & $-3.367(-7.161-2.087)^{\mathrm{a}}$ & $-2.500(-4.160-1.231)$ & $-4.300(-8.105-0.568)^{\mathrm{a}}$ & $-1.550(-6.121-4.404)$ \\
RP & $-6.920(-11.660--1.587)^{\mathrm{a}}$ & $-0.867(-6.815-4.831)$ & $1.016(-1.000-4.000)$ & $-3.200(-8.479-0.864)$ & $-5.450(-15.990-2.192)$ \\
BP & $-13.61(-16.165--10.995)^{\mathrm{a}}$ & $2.106(0.148-6.203)$ & $-2.75(-4.320-1.090)^{\mathrm{a}}$ & $0.3(-1.802-2.451)$ & $-1.200(-9.579-4.354)$ \\
GH & $-10.490(-12.468--8.64)^{\mathrm{a}}$ & $1.100(-1.306-3.585)$ & $1.013(0.000-3.000)$ & $0.1(-1.5-1.375)$ & $-0.65(-4.933-3.032)$ \\
VT & $-9.860(-15.036--5.434)^{\mathrm{a}}$ & $0.378(-4.333-5.863)$ & $2.014(-1.333-7)$ & $1.100(-1.572-3.56)$ & $-3.650(-10.200-3.005)$ \\
SF & $-2.110(-6.396-1.769)$ & $2.567(-1.817-6.906)$ & $2.005(0.000-4.000)$ & $-2.600(-5.774-0.883)$ & $-2.100(-7.69-3.753)$ \\
RE & $-1.550(-5.950-2.946)$ & $-0.789(-6.355-3.949)$ & $1.002(-1.000-4.000)$ & $-2.900(-7.167-0.941)$ & $-5.150(-14.099-1.831)$ \\
MH & $-12.590(-15.331--9.54)^{\mathrm{a}}$ & $-0.106(-1.206-0.119)$ & $-2.750(-3.387-1.000)^{\mathrm{a}}$ & $0.300(-2.577-2.669)$ & $-1.200(-8.82-4.999)$ \\
\hline
\end{tabular}

${ }^{a} \mathrm{P}<0.05$. GH, general health; PF, physiological function; RP, role physical; BP, body pain; VT, vitality; SF, social function; RE, role emotional; $\mathrm{MH}$, mental health.

Table 5 Multi-factor analysis of the GIQLI scores [n=194, OR (95\% CI)]

\begin{tabular}{|c|c|c|c|c|c|}
\hline Variable & Complications occurred & $\begin{array}{l}\text { Hyperamylasemia acute } \\
\text { pancreatitis }\end{array}$ & Acute pancreatitis & Cholecystitis & $\begin{array}{l}\text { Gastrointestinal } \\
\text { bleeding }\end{array}$ \\
\hline Conscious symptoms & $-20.03(-27.887--12.866)^{a}$ & $10.706(2.77-19.62)^{\mathrm{a}}$ & $10.75(5-19)^{a}$ & $7.9(4-11.135)^{\mathrm{a}}$ & $-1.35(-10.5-7.555)$ \\
\hline Social activity status & $0.39(-7.695-5.509)$ & $-1.889(-7.195-6.055)$ & $-0.5(-5-8)$ & $-1.5(-3.141-0.333)$ & $-3.5(-9.526-4.4)$ \\
\hline
\end{tabular}

${ }^{\mathrm{a}} \mathrm{P}<0.05$. GH, general health; PF, physiological function; RP, role physical; BP, body pain; VT, vitality; SF, social function; RE, role emotional; $\mathrm{MH}$, mental health.

the requirements for endoscopists are high. The advent and vigorous development of this technology has benefited many patients. However, during and after ERCP, there is an inevitable risk of surgery-related complications, and serious complications can threaten the lives of patients. Common complications include pancreatitis, perforation, hemorrhage, cholangitis, etc., but also include acute cholecystitis, related cardiopulmonary complications, duodenal hematoma, and other complications with a low incidence. In this study, it was found that the incidence of hyperamylase was the highest $(9.3 \%)$, followed by acute pancreatitis $(5.7 \%)$, and then cholecystitis $(2.6 \%)$, which is similar to previously reported results (12-14,25).

Quality of life can fully reflect the patient's health status. Compared to previous doctors paying more attention to the rates of surgical success patient survival, this study conducted a quality of life assessment, which is more conducive to understanding the quality of life of patients after surgery as well as the long-term impacts of complications. In this study, the SF-36 and GIQLI scores of patients with complications were lower than those of patients without complications.
Clearly, the occurrence of complications or ERCP has a certain impact on the quality of life of patients after surgery. Moreover, in the various dimensions of SF-36 and GIQLI, the occurrence of complications had a greater impact on the patients' conscious symptoms.

The occurrence of complications increases the patient's pain and prolongs their hospital stay. Complications such as hyperamylase and pancreatitis are caused by injury to the pancreatic duct and the appearance of edema. It is worth reiterating that during the nursing process, the patient should be instructed to take a half-recumbent rest as much as possible. Also, a professional and personalized diet plan should be developed according to the patient's blood amylase and routine blood results, so that the patient's nutritional status and gastrointestinal function can be improved as soon as possible, thereby shortening the rehabilitation process.

The main cause of biliary tract infection is failure or incomplete bile drainage, followed by biliary obstruction caused by bacterial infection. Postoperatively, the drainage tube should be properly fixed, the drainage fluid should be recorded, and the patient's vital signs should be closely 
observed, if there are any symptoms of jaundice, and attention should be paid to the cleanliness of the equipment used by the patient and disinfection of the environment.

Bleeding and perforation of the digestive tract are serious complications after ERCP, which seriously threaten the lives and health of patients. Intraoperative sphincter incision, postoperative gastrointestinal pressure, and infection are the reasons for this complication. During the nursing process, the patient should be instructed to stay in bed and eat a reasonable meal. Also, attention should be paid to the patient's personal hygiene, and nurses should immediately inform doctors to take measures to treat patients with abdominal pain and other adverse symptoms. Predictive nursing is a kind of nursing measures for prevention and intervention of possible complications in advance. The purpose is to early predict the possible complications, and to take reasonable and effective targeted nursing in clinical practice. Studies found that $(26,27)$ targeted predictive nursing can reduce the incidence of complications after ERCP, and improve the nursing satisfaction of patients. A professional and effective nursing model can make the patient feel comfortable in the physical, psychological, and social aspects. Specifically, it can minimize psychological and physical pain, enhance the patient's self-confidence in fighting the disease, improve treatment compliance, and ensure the smooth progress of the surgical treatment process, thereby improving the curative effect of surgery, which can reduce the occurrence of complications and improve the quality of life of patients after surgery.

The quality of life of CBDS patients after ERCP with complications is poor after discharge, which suggests that nurses need to take effective measures to prevent and actively treat common complications, such as hyperamylase, acute pancreatitis, and cholecystitis, during the hospitalization of CBDS patients after ERCP in order to promote the recovery of patients and reduce the impact of diseases on the quality of life of patients.

\section{Study limitations}

This study has some shortcomings that should be noted. Firstly, the study is a single-center study with a small sample size, and thus, there may be selection bias. Secondly, the quality of life of patients may be affected by other socioeconomic factors, such as marital status, family income, etc. In future studies, we will broaden the analysis of influencing factors, extend the follow-up time, and further explore the relationship between complications and quality of life.

\section{Acknowledgments}

Funding: None.

\section{Footnote}

Reporting Checklist: The authors have completed the STROBE reporting checklist. Available at https://dx.doi. org/10.21037/apm-21-1373

Data Sharing Statement: Available at https://dx.doi. org/10.21037/apm-21-1373

Conflicts of Interest: All authors have completed the ICMJE uniform disclosure form (available at https://dx.doi. org/10.21037/apm-21-1373). The authors have no conflicts of interest to declare.

Ethical Statement: The authors are accountable for all aspects of this work in ensuring that any questions related to the accuracy or integrity of any part of the work are appropriately investigated and resolved. This study was approved by the Ethics Committee of the Second Affiliated Hospital of Soochow University ([2017]311) and was conducted in accordance with the Declaration of Helsinki (as revised in 2013). All participants provided informed consent.

Open Access Statement: This is an Open Access article distributed in accordance with the Creative Commons Attribution-NonCommercial-NoDerivs 4.0 International License (CC BY-NC-ND 4.0), which permits the noncommercial replication and distribution of the article with the strict proviso that no changes or edits are made and the original work is properly cited (including links to both the formal publication through the relevant DOI and the license). See: https://creativecommons.org/licenses/by-nc-nd/4.0/.

\section{References}

1. Zhu J, Sun G, Hong L, et al. Laparoscopic common bile duct exploration in patients with previous upper abdominal surgery. Surg Endosc 2018;32:4893-9.

2. Cai JS, Qiang S, Yin BB. Advances of recurrent risk factors and management of cho-ledocholithiasis. Scand J Gastroenterol 2017;52:34-43.

3. Williams E, Beckingham I, El Sayed G, et al. Updated guideline on the management of common bile duct stones (CBDS). Gut 2017;66:765-82. 
4. Li P, Wang Y, Wang W. Chinese ERCP guidelines (2018 Edition). Chinese Journal of Digestive Endoscopy 2018;35:777-813.

5. Mallick R, Rank K, Ronstrom C, et al. Single-session laparoscopic cholecystectomy and ERCP: a valid option for the management of choledocholithiasis. Gastrointest Endosc 2016;84:639-45.

6. Ding G, Cai W, Qin M. Single-stage vs. two-stage management for concomitant gallstones and common bile duct stones: a prospective randomized trial with long-term follow-up. J Gastrointest Surg 2014;18:947-51.

7. Molvar C, Glaenzer B. Choledocholithiasis: Evaluation, Treatment, and Outcomes. Semin Intervent Radiol 2016;33:268-76.

8. Mergener K, Kozarek RA. Therapeutic pancreatic endoscopy. Endoscopy 2005;37:201-7.

9. Riff BP, Chandrasekhara V. The Role of Endoscopic Retrograde Cholangiopancrea-tography in Management of Pancreatic Diseases. Gastroenterol Clin North Am 2016;45:45-65.

10. Tumi A, Magadmi M, Elfageih S, et al. ERCP in a cohort of 759 cases: A 6-year expe-rience of a single tertiary centre in Libya. Arab J Gastroenterol 2015;16:25-8.

11. Siiki A, Tamminen A, Tomminen T, et al. ERCP procedures in a Finnish Community Hospital: a retrospective analysis of 1207 cases. Scand J Surg 2012;101:45-50.

12. Freeman ML, Guda NM. Prevention of post-ERCP pancreatitis: a comprehensive review. Gastrointest Endosc 2004;59:845-64.

13. Wu X, Li G, Liu Z. A rare case of duodenum perforation after biliary stenting under endoscopic retrograde cholangiopancreatography: a case report. Ann Transl Med 2020;8:1690.

14. Jeurnink SM, Siersema PD, Steyerberg EW, et al. Predictors of complications after endoscopic retrograde cholangiopancreatography: a prognostic model for early discharge. Surg Endosc 2011;25:2892-900.

15. Chen T, Zhang B, Tang L, et al. Prevention and treatment of complications after therapeutic ERCP. Chinese Journal of General Surgery 2011;20:245-8.

16. Du B, Wang J, Dan J. Analysis and prevention of related complications after ERCP. Chinese Practical Medicine 2012;7:14-6.

17. Moffatt DC, Cote GA, Avula H, et al. Risk factors for ERCPrelated complications in patients with pancreas divisum: a retrospective study. Gastrointest Endosc 2011;73:963-70.

18. Katsinelos P, Lazaraki G, Chatzimavroudis G, et al. Risk factors for therapeutic ERCP-related complications: an analysis of 2,715 cases performed by a single endoscopist. Ann Gastroenterol 2014;27:65-72.

19. Kimura Y, Takada T, Strasberg SM, et al. TG13 current terminology, etiology, and epidemiology of acute cholangitis and cholecystitis. J Hepatobiliary Pancreat Sci 2013;20:8-23.

20. Li S, Su B, Chen P, et al. Risk factors for recurrence of common bile duct stones after endoscopic biliary sphincterotomy. J Int Med Res 2018;46:2595-605.

21. Deng F, Zhou M, Liu PP, et al. Causes associated with recurrent choledocholithiasis following therapeutic endoscopic retrograde cholangiopancreatography: A large sample sized retrospective study. World J Clin Cases 2019;7:1028-37.

22. Yeung SM, Shiu ATY, Martin CR, et al. Translation and validation of the Chinese version of the Gastrointestinal Quality of Life Index in patients with gastric tumor. J Psychosom Res 2006;61:469-77.

23. Korolija D, Sauerland S, Wood-Dauphinee S, et al. Evaluation of quality of life after laparoscopic surgery Evidence-based guidelines of the European Association for Endoscopic Surgery. Surg Endosc 2004;18:879-97.

24. Li L, Wang H, Shen Y. Development and performance test of Chinese version of SF-36 health survey scale. Chinese Journal of Preventive Medicine 2002:38-42.

25. Liu SS, Chang XH, Song JT, et al. Risks of Postendoscopic Retrograde Cholangi-opancreatography Pancreatitis and Hyperamylasemia After Endoscopic Papillary Balloon Dilation: A Retrospective Analysis. Surg Laparosc Endosc Percutan Tech 2019;29:280-4.

26. Zhu Y, Jia P, Wang M. Effect of predictive nursing intervention on postoperative complications of endoscopic retrograde cholangiopancreatography. Chinese Journal of Modern Nursing 2018;24:3200-3.

27. Cheng L. Effect of predictive nursing on prevention of postoperative complications in patients with choledocholithiasis after ERCP. Nursing of integrated traditional Chinese and Western Medicine (Chinese and English) 2016; 2:170-1+4.

(English Language Editor: A. Kassem)

Cite this article as: Huang-Fu L, Qian YH, Qian MJ. The correlation between postoperative complications of ERCP and quality of life after discharge in patients with choledocholithiasis. Ann Palliat Med 2021;10(7):7794-7801. doi: 10.21037/apm-211373 